Research Article

\title{
Utilization of Fly Ash to Enhance Ground Waste Concrete-Based Geopolymer
}

\author{
Wu Chen (iD) ${ }^{1,2}$ and Zhiduo Zhu (iD) ${ }^{1,2}$ \\ ${ }^{1}$ School of Transportation, Southeast University, 210096 Nanjing, China \\ ${ }^{2}$ Province Key Laboratory of Urban Underground Engineering \& Environmental Safety, 210096 Nanjing, China
}

Correspondence should be addressed to Zhiduo Zhu; zhuzhiduo@seu.edu.cn

Received 3 March 2018; Revised 3 June 2018; Accepted 5 July 2018; Published 8 August 2018

Academic Editor: Santiago Garcia-Granda

Copyright (c) $2018 \mathrm{Wu}$ Chen and Zhiduo Zhu. This is an open access article distributed under the Creative Commons Attribution License, which permits unrestricted use, distribution, and reproduction in any medium, provided the original work is properly cited.

\begin{abstract}
Demolition of the deteriorating infrastructure produces a large amount of waste concrete. Storage of waste concrete involves costly transportation, consumption of limited landfill space, and serious environmental problems. Combining them, the recycling of waste concrete is mainly limited to the use of recycled aggregates in the nonstructural filler and base course. Considering the limited geopolymerization potential of waste concrete, this study investigates the feasibility of using fly ash to enhance ground waste concrete-based geopolymer to recycle and utilize waste concrete in high-specification applications. The unconfined compressive strength of the binders synthesized at different fly ash contents, $\mathrm{NaOH}$ concentrations, and curing time are evaluated. Scanning electron microscopy/energy dispersive spectroscopy imaging, X-ray diffraction analyses, Fourier Transform Infra Red analyses, and Magic Angle Spinning-Nuclear Magnetic Resonance Spectroscopy techniques are also conducted to investigate the microstructure and phase/elemental compositions of the synthesized geopolymeric binders. The results indicate that the addition of fly ash to ground waste concrete profoundly enhances the strength of ground waste concrete-based geopolymer up to $75 \%$ fly ash content. The simultaneous formation of geopolymeric gel and CSH gel is responsible for the strength increase. The geopolymeric binder with required strength can be produced by the appropriate addition of fly ash to ground waste concrete.
\end{abstract}

\section{Introduction}

Concrete, consisting of Portland cement, sand, and aggregates, is the most widely used construction material. However, the manufacturing process of Portland cement, sand, and aggregates is usually associated with high consumption of energy, emission of $\mathrm{CO}_{2}$, consumption of nonrenewable natural resources $[1,2]$. Due to the growing awareness of environmental protection and sustainable development, the alternative low-cost and eco-friendly materials have been sought by the construction industry [3].

There has been an enormous increase of waste concrete (WC) in China during last decades due to the demolition of the deteriorating infrastructure. How to appropriately dispose off WC has been a great concern [4]. Most of the generated WC is disposed in landfill, which involves costly transportation, consumption of limited landfill space, and serious environmental problems [5]. Therefore, recycling of WC is encouraged by different institutions, and extensive research has been conducted $[6,7]$. However, recycling of WC in the current practice is limited to the use of recycled aggregates in nonstructural filler and base course $[8,9]$. The recycled aggregate has high water absorption, high emission of dust, low specific gravity and bulk density, and inferior mechanical properties in comparison to the natural aggregate. The adhered mortar/paste on the recycled aggregate is the main reason for these inferior properties and thwart the wide use of recycled aggregate to largely replace natural aggregate in the production of new concrete as it affects the strength and durability of the new concrete. To address this issue, some aggregate refining methods such as "freezethaw," "thermal expansion," and "mechanical grinding" [10-12] have been proposed to refine the quality of recycled aggregates by eliminating the adhered mortar but keeping 
the integrity of natural coarse aggregate. However, these techniques involve complicated procedure, high energy consumption, and most importantly they produce additional fines which need to be disposed of. Very few researchers $[13,14]$ have investigated complete recycling of waste concrete, but these methods require the reclinkering process at high temperature and thus consume significant amount of energy and generate tremendous amount of greenhouse gas.

Recently, an inorganic binder, named geopolymer, has attracted the attention of researchers from different engineering disciplines. Geopolymer has an amorphous to poor order polymeric structure synthesized from the reaction of a solid aluminosilicate with a high $\mathrm{pH}$ alkaline solution. Geopolymer possesses many merits over Portland cement such as rapid mechanical strength development, excellent adherence to aggregates, and lower $\mathrm{CO}_{2}$ emissions and energy consumption. Researchers have applied this technology to produce geopolymer products from different raw materials, including fly ash, slag, and mine tailing [15-17].

Komnitsas et al. [18] have investigated using WC powder to produce geopolymeric binder. However, the WC showed limited geopolymerization potential and had a compressive strength of only $13 \mathrm{MPa}$. The high content of $\mathrm{CaO}$ in waste concrete impedes the geopolymerization of $\mathrm{WC}$ as it depletes alkaline hydroxide and forms brittle and soluble pirssonite $\left(\mathrm{Na}_{2} \mathrm{CO}_{3} \cdot \mathrm{CaCO}_{3} \cdot 2 \mathrm{H}_{2} \mathrm{O}\right)$.

The previous research [19] showed that metakaolin profoundly enhanced the strength of ground WC-based geopolymer; however, metakaolin is from kaolinite clay from the ground and is known for its high cost. So, this paper investigates the feasibility of using fly ash (FA) to enhance WC-based geopolymer so that WC can be recycled and utilized in high-specification applications. Sodium hydroxide $(\mathrm{NaOH})$ solution mixed with sodium silicate solution is used as an alkaline reaction agent. The unconfined compressive strengths (UCS) of the geopolymeric binders synthesized at different $\mathrm{NaOH}$ solution concentrations, FA contents, and curing time are measured. Scanning electron microscopy/energy dispersive spectroscopy (SEM/EDS) imaging, X-ray diffraction (XRD), Fourier Transform Infra Red (FTIR) analyses, and Magic Angle Spinning-Nuclear Magnetic Resonance Spectroscopy (MAS-NMR) analyses are also conducted to study the microstructure and phase/elemental compositions of the synthesized binder.

\section{Materials and Methods}

2.1. Materials. Ground WC, FA, reagent grade $98 \% \mathrm{NaOH}$, sodium silicate solution, and deionized water were used in this study. Ground WC was produced from the tested Portland cement concrete specimens in the structural lab of Southeast University. The tested concrete specimens were firstly crushed into two parts based on the particle size by a jaw crusher, and then the fine part passing mesh $32(0.5 \mathrm{~mm})$ was grinded by a ball mill to make most particles pass mesh 200. FA was received from Yangzhou Power Plant, China. The chemical components of ground WC and FA determined by X-ray fluorescence are presented in Table 1 . The $\mathrm{NaOH}$ pellets
TABLE 1: Chemical components of WC and FA determined by XRF analysis.

\begin{tabular}{lcc}
\hline Component (wt.\%) & WC & FA \\
\hline $\mathrm{SiO}_{2}$ & 38.81 & 54.85 \\
$\mathrm{CaO}$ & 21.91 & 6.21 \\
$\mathrm{Al}_{2} \mathrm{O}_{3}$ & 9.99 & 24.48 \\
$\mathrm{Fe}_{2} \mathrm{O}_{3}$ & 3.5 & 4.85 \\
$\mathrm{~K}_{2} \mathrm{O}$ & 1.63 & 1.13 \\
$\mathrm{MgO}$ & 1.63 & 0.89 \\
$\mathrm{Na}_{2} \mathrm{O}$ & 0.74 & 0.61 \\
\hline
\end{tabular}

and the sodium silicate solution $\left(\mathrm{Na}_{2} \mathrm{O}=8.52\right.$ wt. $\%, \mathrm{SiO}_{2}=$ 27.28 wt.\%, $\mathrm{H}_{2} \mathrm{O}=64.2$ wt.\%, modulus $\left.\left(\mathrm{SiO}_{2} / \mathrm{Na}_{2} \mathrm{O}\right)=3.1\right)$ were purchased from a $\mathrm{ZD}$ chemical company (in China).

Figure 1 presents the particle size distribution curves of the ground WC and FA determined by a Hydro $2000 \mathrm{Mu}$ Melvin Laser Diffraction Particle Size Analyzer (the particles were suspended in deionized water). The D50 of ground WC is $8.3 \mu \mathrm{m}$ with about $90 \%$ particles finer than $75 \mu \mathrm{m}$ while the D50 of FA is $9.5 \mu \mathrm{m}$ with about $96 \%$ particles finer than $75 \mu \mathrm{m}$. Figure 2 shows the microstructure of ground WC and FA photographed by SEM. The shape of WC particles is angular while the FA particles have a sphere shape.

2.2. Methods. Dry ground WC and FA at a given FA content were completely mixed. Simultaneously, the $\mathrm{NaOH}$ pellets were dissolving in deionized water at a selected concentration to prepare $\mathrm{NaOH}$ solution. The cooled down $\mathrm{NaOH}$ solution was added into the sodium silicate solution at a sodium silicate solution/ $\mathrm{NaOH}$ solution (SS/N) mass ratio of 1.5 and stirred in a cement/mortar mixer at the rate of $60 \mathrm{r} / \mathrm{min}$ for $2 \mathrm{~min}$. The well-stirred activator was mixed with the WC/FA mixture at a liquid to solid $(\mathrm{L} / \mathrm{S})$ weight ratio of 0.4 . The resulting mixture was stirred for $5 \mathrm{~min}$ to facilitate dissolution of more $\mathrm{Si}, \mathrm{Al}$, and $\mathrm{Ca}$ in the liquid phase. The resulting paste was poured in cubic iron molds (length $=20 \mathrm{~mm}$ ) and then shaken for $2 \mathrm{~min}$ to remove air bubbles. Then, the molds were capped and cured at $50^{\circ} \mathrm{C}$ for $24 \mathrm{~h}$ for setting. The specimens were demolded and placed in plastic bags and cured at ambient temperature before being tested. The specimen preparation method for all specimens was consistent. The size of the specimen was much smaller than the one required in the Chinese Standard for test method of mechanical properties on ordinary concrete (GB/T 50018-2002). Therefore, the UCS results should not be interpreted in absolute but rather in relative terms. As presented in Figures 3-5, the standard deviation in UCS is small.

Unconfined compression tests were conducted on the cured specimens with a CBR-2 press machine at a constant strain rate of $1.27 \mathrm{~mm} / \mathrm{min}$. For each recipe, three specimens were tested, and the average values were reported. The end faces of the specimens were polished to ensure parallelism and smoothness. SEM/EDS, XRD, and FTIR were used to inspect the microstructure and phase composition of geopolymers. SEM/EDS analysis was performed using a HITACHI SU3500 scanning electron microscope. The XRD analysis was conducted in a PANALYTICAL X'Pert PRO MRD/XL diffractometer, FTIR analysis was using 


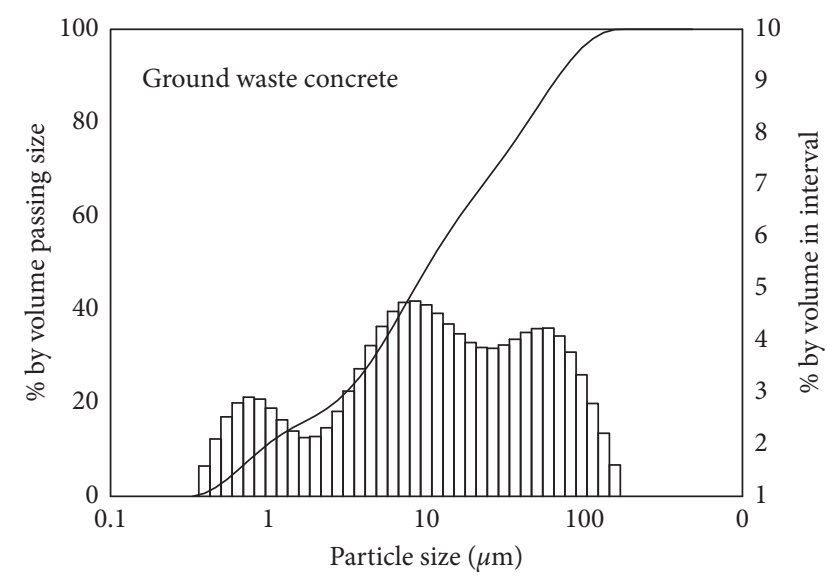

(a)

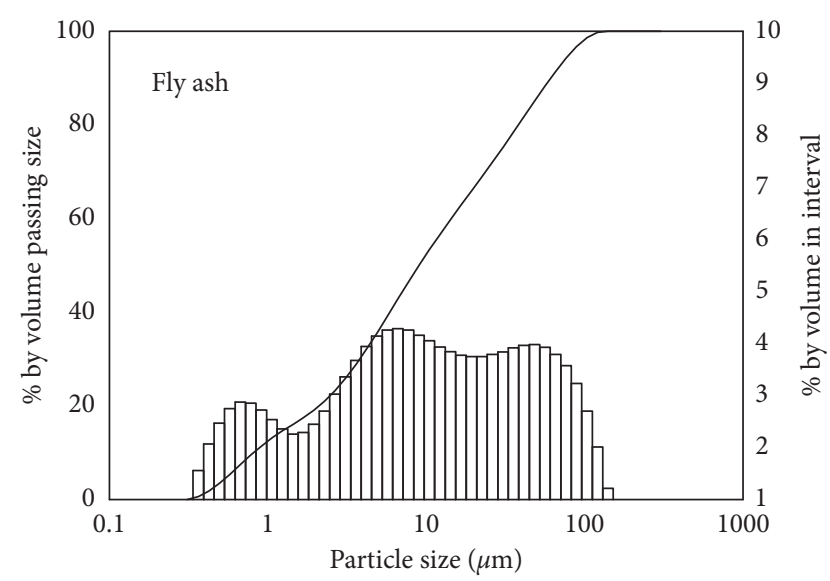

(b)

Figure 1: Particle size distribution of fly ash (a) and ground waste concrete (b).

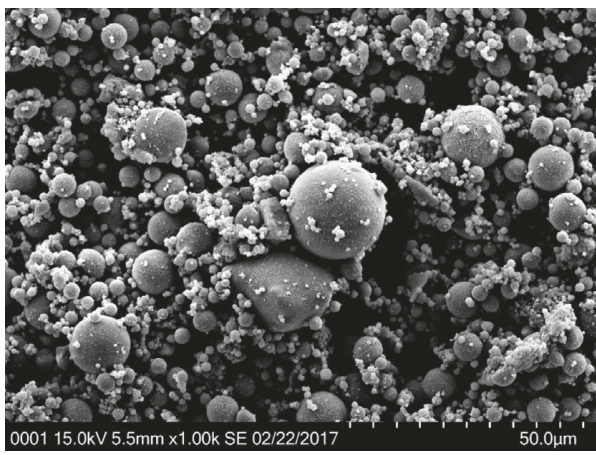

(a)

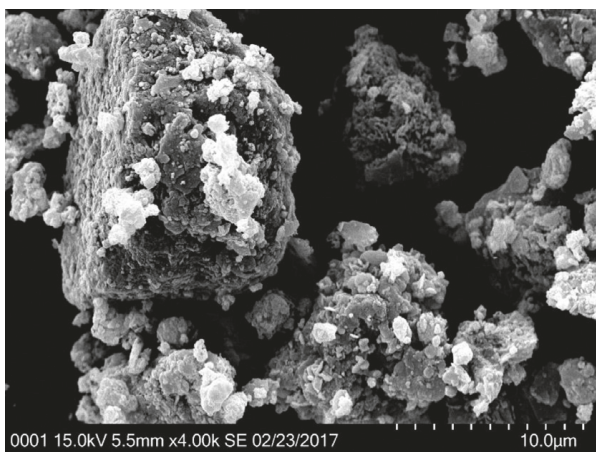

(c)

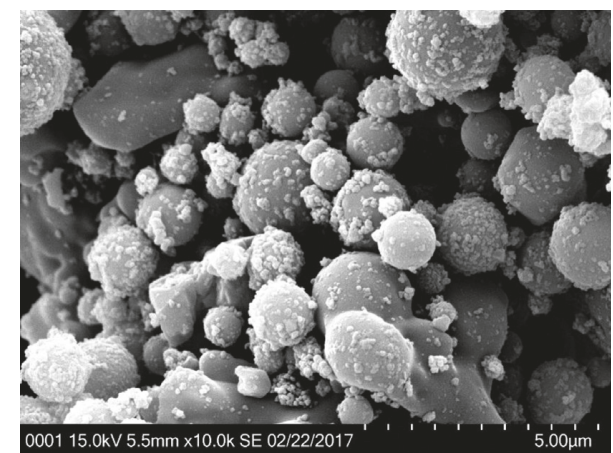

(b)

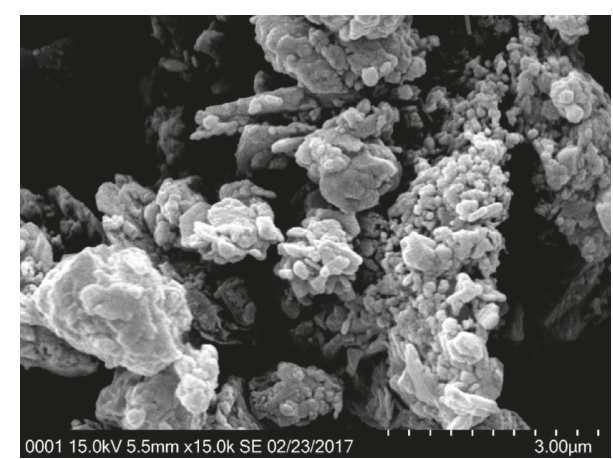

(d)

FIgURE 2: SEM micrographs of fly ash (FA)—(a, b) and waste concrete (WC) - (c, d).

Thermo Nicolet 370 FTIR/EZ Omnic, and MAS-NMR analysis was using a JEOL NM-ESH40MU Nuclear Magnetic Resonance Spectroscopy.

The variables proportion mixture and conducted test are presented in Table 2.

\section{Results and Discussion}

3.1. UCS. This study investigated the effects of $\mathrm{NaOH}$ concentration, FA content, and curing time on the UCS of the geopolymer binder.
3.1.1. Effect of $\mathrm{NaOH}$ Concentration. Two mechanisms may explain the roles of $\mathrm{NaOH}$ in the geopolymeric reaction: dissolution of $\mathrm{Si}$ and $\mathrm{Al}$ species and charge-balancing of $\mathrm{Al}$ species [20], which can be presented chemically as follows [21]:

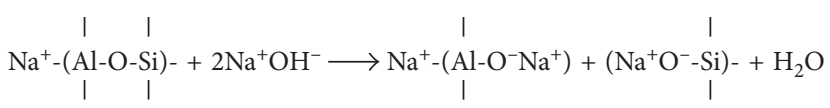

As shown in Figure 3, the UCS values increase as $\mathrm{NaOH}$ concentration increases from $10 \mathrm{M}$ to $14 \mathrm{M}$, which is also 


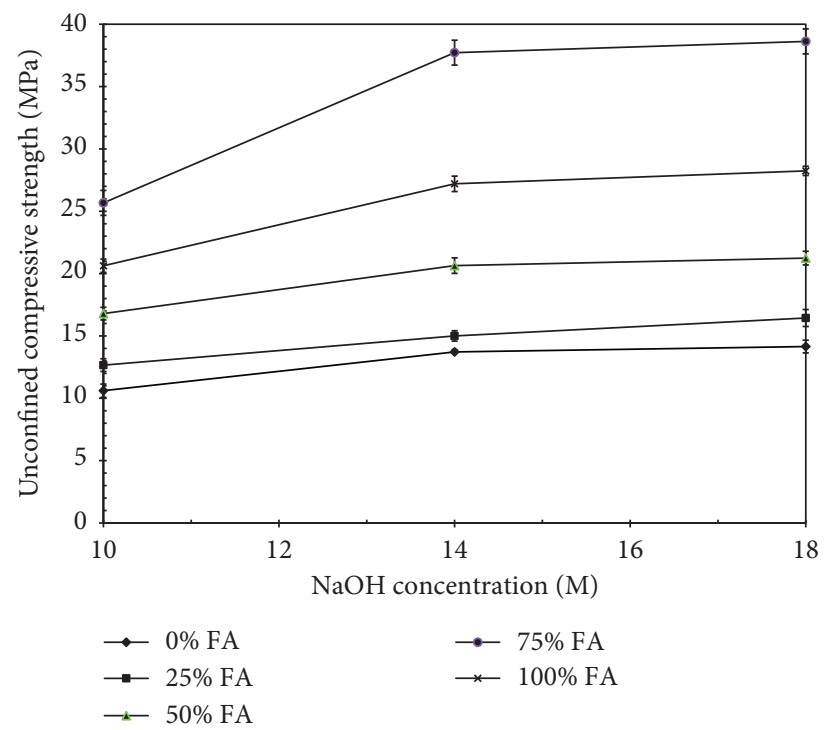

FIgURE 3: 7 days UCS versus $\mathrm{NaOH}$ concentration with different FA contents.

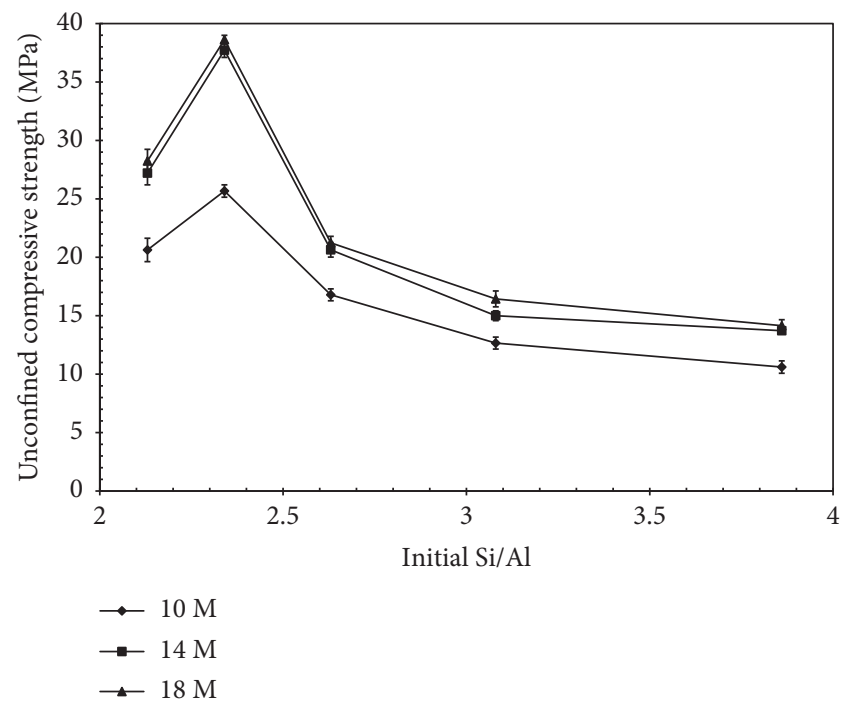

FIgUre 4: 7-day UCS versus initial $\mathrm{Si} / \mathrm{Al}$ at different $\mathrm{NaOH}$ concentration.

reported by Ahmari et al. [21]. This trend may be explainable knowing the fact that more $\mathrm{Si}$ and $\mathrm{Al}$ are dissolved at higher $\mathrm{NaOH}$ concentration and thus incorporation of lager amount of $\mathrm{Si}$ and $\mathrm{Al}$ in geopolymerization. However, some researchers have found a parabolic relationship between $\mathrm{NaOH}$ concentration and UCS [22]. The UCS firstly increases as $\mathrm{NaOH}$ concentration increases and then decreases after $\mathrm{NaOH}$ exceeds a certain value. That parabolic relationship may be attributed to the excess $\mathrm{Na}^{+}$presented in the geopolymer framework and adversely affect the properties of geopolymers [23].

Another possibility for the UCS increase with alkalinity up to at least $14 \mathrm{M}$ may be attributed to CSH gels formation as a result of the pozzolanic reactions. Different researchers [24-26] have reported high alkalinity, and present sufficient calcium leads to $\mathrm{CSH}$ formation. Since the WC contains

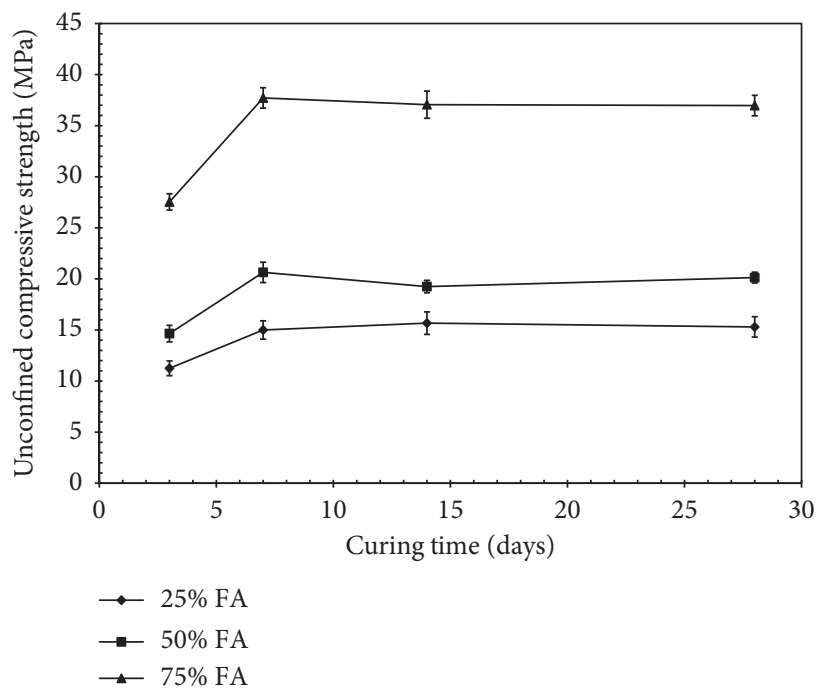

FIgURE 5: UCS versus curing time with different FA content at M $\mathrm{NaOH}$ concentration.

substantial quantities of calcium, CSH might have formed filling the voids in the matrix and thus leading to higher UCS. However, the CSH formation is different at low and high alkalinity $[24,25]$. Calcium can be easily dissolved for forming $\mathrm{CSH}$ at low alkalinity. At high alkalinity, $\mathrm{OH}^{-}$ions will hinder the dissolution of calcium but the geopolymeric reaction and incorporation of $\mathrm{OH}^{-}$in the geopolymerization decrease the alkalinity and thus lead to calcium leaching and $\mathrm{CSH}$ forming $[24,25]$.

The second mechanism is to provide $\mathrm{Na}^{+}$to chargebalance the $\mathrm{Al}$ species and thus the $\mathrm{Na} / \mathrm{Al}$ ratio is important display the availability of $\mathrm{Na}^{+}$for $\mathrm{Al}$ atom. In the current investigation, the $\mathrm{Na} / \mathrm{Al}$ ratios ranges from 0.39 to 1.31 listed in Table 2. Researchers have investigated different materials with $\mathrm{Na} / \mathrm{Al}$ ratios varying from 0.38 to 2.06 , and a $\mathrm{Na} / \mathrm{Al}$ ratio around 1 is recommended [21-23, 27]. Excess $\mathrm{Na}^{+}$ 
TABLE 2: Variables and conducted tests on WC/FA specimens.

\begin{tabular}{|c|c|c|c|c|c|c|c|c|c|c|c|c|c|c|}
\hline Specimens & $\begin{array}{l}\text { FA } \\
(\%)\end{array}$ & $\begin{array}{l}\mathrm{NaOH} \text { conc. } \\
(\mathrm{M})\end{array}$ & $\mathrm{SS} / \mathrm{N}$ & $\mathrm{L} / \mathrm{S}$ & $\mathrm{Si} / \mathrm{Al}^{\mathrm{b}}$ & $\mathrm{Ca} / \mathrm{Si}^{\mathrm{b}}$ & $\mathrm{Na} / \mathrm{Al}^{\mathrm{b}}$ & $\mathrm{Na} / \mathrm{Si}$ & $\begin{array}{l}\text { Curing } \\
\text { time/days }\end{array}$ & $\begin{array}{l}\text { UCS } \\
\text { test }\end{array}$ & XRD & SEM/EDS & FTIR & $\begin{array}{l}\text { MAS- } \\
\text { NMR }\end{array}$ \\
\hline WC & 0 & & & & 3.30 & 0.60 & & & & & $\sqrt{ }$ & & $\sqrt{ }$ & \\
\hline FA & 100 & & & & 1.90 & 0.12 & & & & & $\sqrt{ }$ & & $\sqrt{ }$ & \\
\hline $0 \_10-^{\mathrm{a}}$ & 0 & 10 & 1.5 & 0.40 & 3.86 & 0.52 & 0.96 & 0.25 & 7 & $\sqrt{ }$ & & & & \\
\hline $2 \overline{5} \_10 \_7$ & 25 & 10 & 1.5 & 0.40 & 3.08 & 0.39 & 0.70 & 0.23 & 7 & $\sqrt{ }$ & & & & \\
\hline 50_10_7 & 50 & 10 & 1.5 & 0.40 & 2.63 & 0.28 & 0.56 & 0.21 & 7 & $\sqrt{ }$ & & & & \\
\hline 75_10_7 & 75 & 10 & 1.5 & 0.40 & 2.34 & 0.19 & 0.46 & 0.20 & 7 & $\sqrt{ }$ & & & & \\
\hline 100_10_7 & 100 & 10 & 1.5 & 0.40 & 2.13 & 0.11 & 0.39 & 0.18 & 7 & $\sqrt{ }$ & & & & \\
\hline $0 \_14 \_7$ & 0 & 14 & 1.5 & 0.40 & 3.86 & 0.52 & 1.13 & 0.29 & 7 & $\sqrt{ }$ & $\sqrt{ }$ & & & \\
\hline $2 \overline{5} \_14 \_3$ & 25 & 14 & 1.5 & 0.40 & 3.08 & 0.39 & 0.83 & 0.27 & 3 & $\sqrt{ }$ & & & & \\
\hline 25_14_7 & 25 & 14 & 1.5 & 0.40 & 3.08 & 0.39 & 0.83 & 0.27 & 7 & $\sqrt{ }$ & & & & \\
\hline 25_14_14 & 25 & 14 & 1.5 & 0.40 & 3.08 & 0.39 & 0.83 & 0.27 & 14 & $\sqrt{ }$ & & & & \\
\hline 25_14_28 & 25 & 14 & 1.5 & 0.40 & 3.08 & 0.39 & 0.83 & 0.27 & 28 & $\sqrt{ }$ & & & & \\
\hline 50_14_3 & 50 & 14 & 1.5 & 0.40 & 2.63 & 0.28 & 0.66 & 0.25 & 3 & $\sqrt{ }$ & & & & \\
\hline 50_14_7 & 50 & 14 & 1.5 & 0.40 & 2.63 & 0.28 & 0.66 & 0.25 & 7 & $\sqrt{ }$ & & & & \\
\hline 50_14_14 & 50 & 14 & 1.5 & 0.40 & 2.63 & 0.28 & 0.66 & 0.25 & 14 & $\sqrt{ }$ & & & & \\
\hline 50_14_28 & 50 & 14 & 1.5 & 0.40 & 2.63 & 0.28 & 0.66 & 0.25 & 28 & $\sqrt{ }$ & & & & \\
\hline 75_14_3 & 75 & 14 & 1.5 & 0.40 & 2.34 & 0.19 & 0.54 & 0.23 & 3 & $\sqrt{ }$ & & & & \\
\hline 75_14_7 & 75 & 14 & 1.5 & 0.40 & 2.34 & 0.19 & 0.54 & 0.23 & 7 & $\sqrt{ }$ & $\sqrt{ }$ & $\sqrt{ }$ & $\sqrt{ }$ & $\sqrt{ }$ \\
\hline 75_14_14 & 75 & 14 & 1.5 & 0.40 & 2.34 & 0.19 & 0.54 & 0.23 & 14 & $\sqrt{ }$ & & & & \\
\hline 75_14_28 & 75 & 14 & 1.5 & 0.40 & 2.34 & 0.19 & 0.54 & 0.23 & 28 & $\sqrt{ }$ & & & & \\
\hline 100_14_7 & 100 & 14 & 1.5 & 0.40 & 2.13 & 0.11 & 0.46 & 0.22 & 7 & $\sqrt{ }$ & $\sqrt{ }$ & & & \\
\hline $0 \_18 \_7$ & 0 & 18 & 1.5 & 0.40 & 3.86 & 0.52 & 1.31 & 0.34 & 7 & $\sqrt{ }$ & & & & \\
\hline $25 \_18 \_7$ & 25 & 18 & 1.5 & 0.40 & 3.08 & 0.39 & 0.96 & 0.31 & 7 & $\sqrt{ }$ & & & & \\
\hline 50_18_7 & 50 & 18 & 1.5 & 0.40 & 2.63 & 0.28 & 0.76 & 0.29 & 7 & $\sqrt{ }$ & & & & \\
\hline 75_18_7 & 75 & 18 & 1.5 & 0.40 & 2.34 & 0.19 & 0.63 & 0.27 & 7 & $\sqrt{ }$ & & & & \\
\hline 100_18_7 & 100 & 18 & 1.5 & 0.40 & 2.13 & 0.11 & 0.54 & 0.25 & 7 & $\sqrt{ }$ & & & & \\
\hline
\end{tabular}

${ }^{\mathrm{a}} 0 \_10 \_7$ means specimen at $0 \% \mathrm{FA}, 10 \mathrm{M} \mathrm{NaOH}$ concentration, and 7 days of curing. ${ }^{\mathrm{b}} \mathrm{Si} / \mathrm{Al}, \mathrm{Ca} / \mathrm{Si}$, and $\mathrm{Na} / \mathrm{Al}$ are atom ratios.

presented in the polymeric framework leads to adverse effect on the UCS of geopolymers [27]. This may explain the current observation that the UCS keeps almost constant as $\mathrm{NaOH}$ concentration increases from $14 \mathrm{M}$ to $18 \mathrm{M}$.

3.1.2. Effect of FA Content. The relationship between UCS and $\mathrm{FA}$ contents can be explained based on the $\mathrm{Si} / \mathrm{Al}$ ratio of the WC/FA mixture. The amount of $\mathrm{Si}$ and $\mathrm{Al}$ in the source material plays a vital role to the synthesis of the geopolymer product as presented in the above scheme [27]. Researchers have investigated the influence of $\mathrm{Si} / \mathrm{Al}$ ratios on geopolymerization $[16,20-23,28,29]$, and the optimal value may change depending on raw materials used in geopolymerization. The $\mathrm{WC}$ and $\mathrm{FA}$ have an initial $\mathrm{Si} / \mathrm{Al}$ ratio of 3.30 and 1.90, respectively, which is not necessarily the same as the reactive ratio in the precursors. By adding FA into WC and utilizing appropriate amount of alkaline reaction agent, the $\mathrm{Si} / \mathrm{Al}$ ratio varies from 2.13 to 3.86 (Figure 4 ). The $\mathrm{Si} / \mathrm{Al}$ ratio of 2.34 (at $75 \% \mathrm{FA}$ used in this study) reaches the highest UCS.

Komnitsas et al. [18] indicated that the high content of $\mathrm{Ca}$ in waste concrete impedes the geopolymerization of waste concrete. In the current study, the high content of $\mathrm{Ca}$ in $\mathrm{WC}(\mathrm{Ca} / \mathrm{Si}=0.60)$ is decreased by adding the FA into the WC. The negative impact of too high $\mathrm{Ca} / \mathrm{Si}$ ratio is primarily attributed to the precipitation of $\mathrm{Ca}(\mathrm{OH})_{2}$ [30]. The highly unstable $\mathrm{Ca}(\mathrm{OH})_{2}$, as a result of atmospheric carbonation, is favored to form calcium carbonate [31]. Simultaneously, Ca species may be hindered to be incorporated in the formation of CSH as the precipitation of $\mathrm{Ca}(\mathrm{OH})_{2}$ [32]. And thus causes a decrease in UCS. However, researchers [33-35] have reported that Ca can improve the strength of geopolymeric binders since $\mathrm{Ca}^{2+}$ serves as a charge-balancing agent in the geopolymeric network and facilitates the formation of calcium silicate hydrate (CSH) gel leading to fill the voids between the phases, which may explain the UCS at $75 \%$ FA $(\mathrm{Ca} / \mathrm{Si}=0.19)$ higher than that of the specimen in the absence of the $\mathrm{WC}(\mathrm{Ca} / \mathrm{Si}=0.11)$. At the highest UCS, the optimal $\mathrm{Ca} / \mathrm{Si}$ in the WC/FA geopolymeric system is 0.19 .

Ahmari et al. [21] investigated the geopolymeric binder from blended waste concrete powder and fly ash. Their results showed that the geopolymers synthesized with $50 \%$ FA and 50\% waste concrete have the highest compressive strength. This may be attributed to that the alkalinity concentration ( 5 to $10 \mathrm{M}$ ) they used is lower than the one used in the current study as higher alkalinity concentration leads to the lager dissolution of $\mathrm{Si}$ and $\mathrm{Al}$ and the formation of $\mathrm{CSH}$ as discussion above.

3.1.3. Effect of Curing Time. Figure 5 shows the UCS of the specimens cured for different curing times. Significant increase in strength was found on these specimens in the first 3 days, and they reached their maximum strength which can be observed by almost constant strength at 7 days and beyond. Due to the specimens cured at $50^{\circ} \mathrm{C}$ for 24 hours, the geopolymeric 


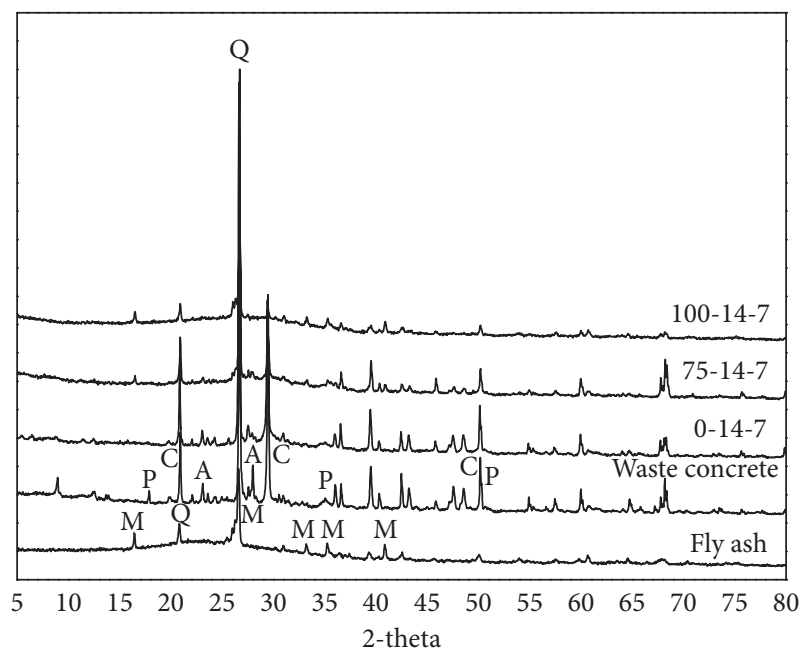

$\begin{array}{ll}\text { M: muscotive } & \text { Q: quartz } \\ \text { A: anorthite } & \text { C: CSH } \\ \text { P: portlandite } & \end{array}$

FIGURE 6: XRD patterns of FA, WC, and the geopolymer specimens produced with, respectively, $0 \%, 75 \%$, and $100 \%$ FA.

reaction was already completed at 7 days. The amorphous phase is the only reason for the increase in strength as the crystalline phase makes no change with time [36].

\subsection{Micro/Nano-Scale Investigation}

3.2.1. XRD Analysis. The results of XRD analysis for the FA, ground $\mathrm{WC}$, and the three geopolymeric specimens synthesized with $0 \%, 75 \%$, and $100 \% \mathrm{FA}$ are presented in Figure 6. FA contains semicrystalline and amorphous phase with a broad hump centered at approximately $22^{\circ}$ along with a low-intensity peak corresponding to quartz and mullite. The ground WC mainly consists of crystalline phases including anorthite, quartz, portlandite, and CSH. In the ground WC, quartz and anorthite are derived from the crushed aggregates. The portlandite and $\mathrm{CSH}$ are the products of the cement hydration. In addition, a weak amorphous phase from $25^{\circ}$ to $40^{\circ}$ is observed in the XRD pattern of the ground WC. The XRD patterns of the specimens synthesized with $75 \%$ and $100 \%$ FA show that the crystalline peaks decrease and the broad humps shift to larger angles. The amorphous hump which extends from $20^{\circ}$ to $40^{\circ}$ is a feature of the geopolymeric gel. The decrease in crystalline peaks is probably because the wt \% of crystalline elements is lower than it is in the powdered product. There is no new crystalline phase being synthesized by geopolymerization of the $75 \%$ FA specimen under the conditions used in this study. That may be attributed to that the crystalline $\mathrm{CSH}$ is not a main synthesized product of the reaction. The same observation has been made by van Jaarsveld et al. [37]. In the XRD pattern of the $0 \%$ FA specimen, the portlandite disappears indicating complete dissolution of the corresponding phase in the ground $\mathrm{WC}$ after geopolymerization. However, the CSH gel shows lower reactivity to the alkaline solution as only a portion of it dissolves. Pirssonite, which is responsible for low compressive strength of the ground WC-based geopolymer [18], is not formed. It may be attributed to the ground WC used in this study that has much lower $\mathrm{CaO}$ content (21.29\%). In addition, the sodium silicate $/ \mathrm{NaOH}$ equals 1.5 in this study while the sodium silicate/ $\mathrm{NaOH}$ equals approximately 1 in Komnitsas et al.'s study. That also explains no pirssonite formed in this study because soluble silicate thwarts the dissolution of Ca-silicate.

3.2.2. FTIR Analysis. The IR spectra of the FA, ground WC, and the 75\% FA specimen are presented in Figure 7. Both FA and ground WC show strong broad bands from $800 \mathrm{~cm}^{-1}$ to $1200 \mathrm{~cm}^{-1}$, which corresponds to the stretching vibrations of $\mathrm{Si}-\mathrm{O}$ bonds [38]. In the IR spectrum of the 75\% FA specimen, the $\mathrm{Si}-\mathrm{O}$ vibration band has two main changes. First, the band shifts to a lower wave number, which is due to the depolymerization of silicates and replacement partial Si with $\mathrm{Al}$ [38], and thus leads to the transformation of $\mathrm{Si}-\mathrm{O}$ band from symmetric to asymmetric form [34]. The Si-O stretching modes for the $\mathrm{SiQ}^{n}$ units show absorption bands centered around $850,900,950,1000$, and $1100 \mathrm{~cm}^{-1}$ for $n=0,1,2,3$, and 4, respectively [34]. These values shift toward lower wave numbers when the degree of substitution of $\mathrm{Si}$ with $\mathrm{Al}$ in the second coordination sphere increases [39]. The second change is the band becomes wider, which is attributed to the formation of randomly distributed $\mathrm{Si}-\mathrm{Al}$ bonds [21]. Beyond that, a new weak band appears at $1400 \mathrm{~cm}^{-1}$, which is due to the polymerization of the dissolved silicates [40]. The band centered at $798 \mathrm{~cm}^{-1}$ in both FA and ground WC IR spectra, corresponding to the $\mathrm{Al}(\mathrm{VI})-\mathrm{O}$ vibration band, vanishes (or weakens) in the $75 \%$ FA IR spectrum, and a new weak band centered at $619 \mathrm{~cm}^{-1}$, corresponding to $\mathrm{Al}(\mathrm{IV})-\mathrm{O}-\mathrm{Si}$ vibration band, appears, which is attributed to the formation of new aluminosilicate phase related to geopolymerization [28]. The noticeable characteristic bands at $3640 \mathrm{~cm}^{-1}$ corresponding to $\mathrm{O}-\mathrm{H}$ vibration of $\mathrm{Ca}(\mathrm{OH})_{2}$ [39] in the IR spectrum of ground WC disappears in the 75\% FA spectrum, which indicates that $\mathrm{Ca}(\mathrm{OH})_{2}$ undergoes full dissolution as confirmed with the XRD analysis.

3.2.3. MAS-NMR Analysis. The ${ }^{29}$ Si MAS-NMR spectrum of the $75 \%$ FA specimen is presented in Figure 8. There is a broad resonance extends from $-70 \mathrm{ppm}$ to $-110 \mathrm{ppm}$ associated with three low-intensity peaks at $-84.2 \mathrm{ppm}$, $-91.6 \mathrm{ppm}$, and $-103.4 \mathrm{ppm}$, respectively. The broad resonance is due to the disordered orientation of the $\mathrm{Si}$ and $\mathrm{Al}$ tetrahedrons. The three small peaks can be assigned to $\mathrm{SiQ}^{4}$ (4Al), $\mathrm{SiQ}^{4}(3 \mathrm{Al})$, and $\mathrm{SiQ}^{4}(4 \mathrm{Si})$ units [41].

3.2.4. SEM/EDS Analysis. Figure 9 shows the SEM/EDS analysis of the $75 \%$ FA specimen, several distinct phases are observed: unreacted and partially reacted FA particles, partially reacted WC particles, two different forms of gel, and those particles embedded in the gel. The major elemental compositions of area $\mathrm{A}$ gel are $\mathrm{Si}, \mathrm{Al}$, and $\mathrm{Na}$ with a trace of $\mathrm{Ca}(1.73$ wt.\%) while in area $\mathrm{B}$ gel, $\mathrm{Si}, \mathrm{Ca}$, and $\mathrm{Na}$ 


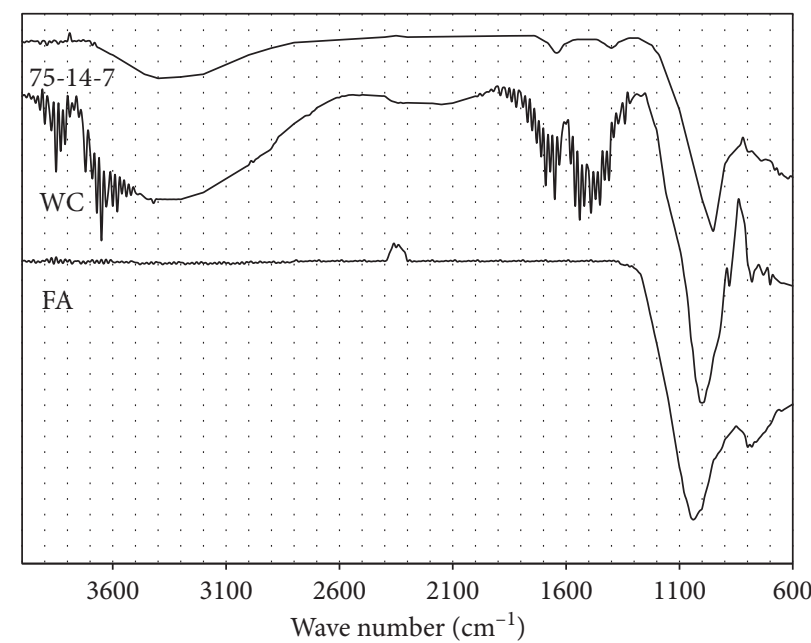

FIGURE 7: IR spectra of FA, WC, and the geopolymer specimen produced at 75\% FA.

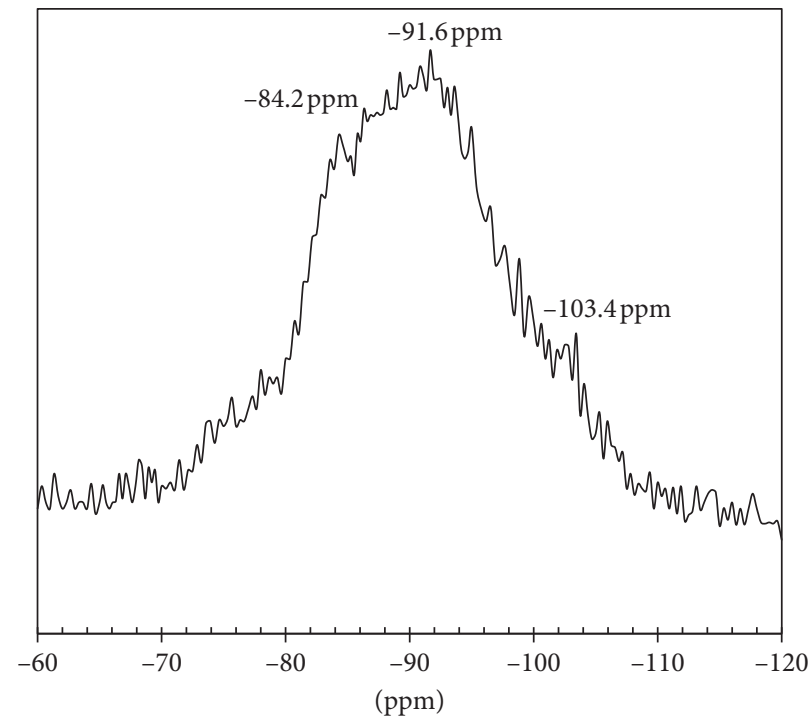

FIGURE $8:{ }^{29} \mathrm{Si}$ MAS-NMR spectrum of the geopolymer specimen produced at $75 \%$ FA.

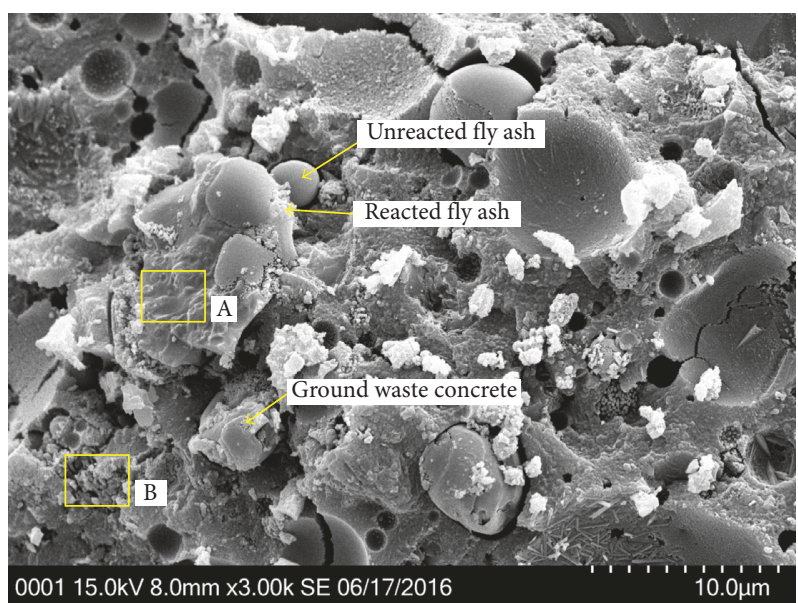

(a)

Figure 9: Continued. 


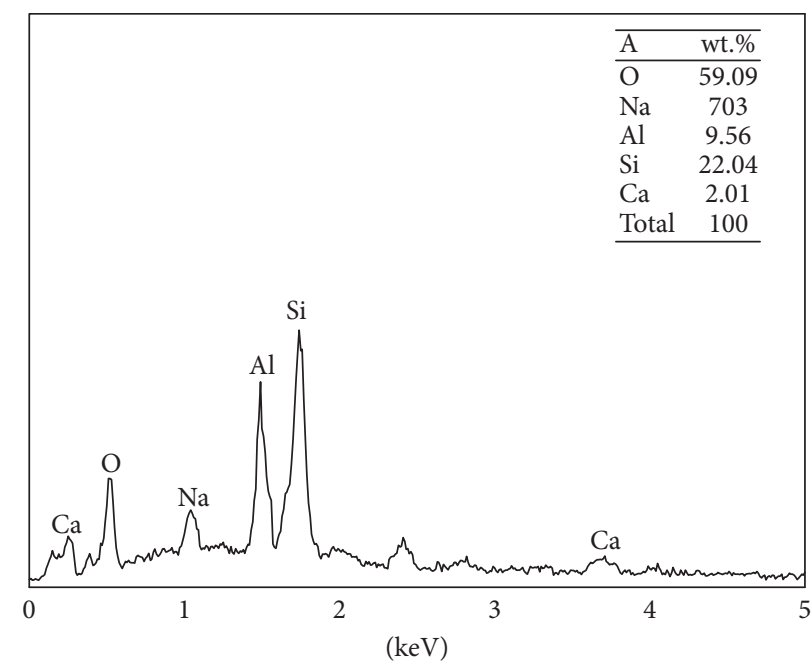

(b)

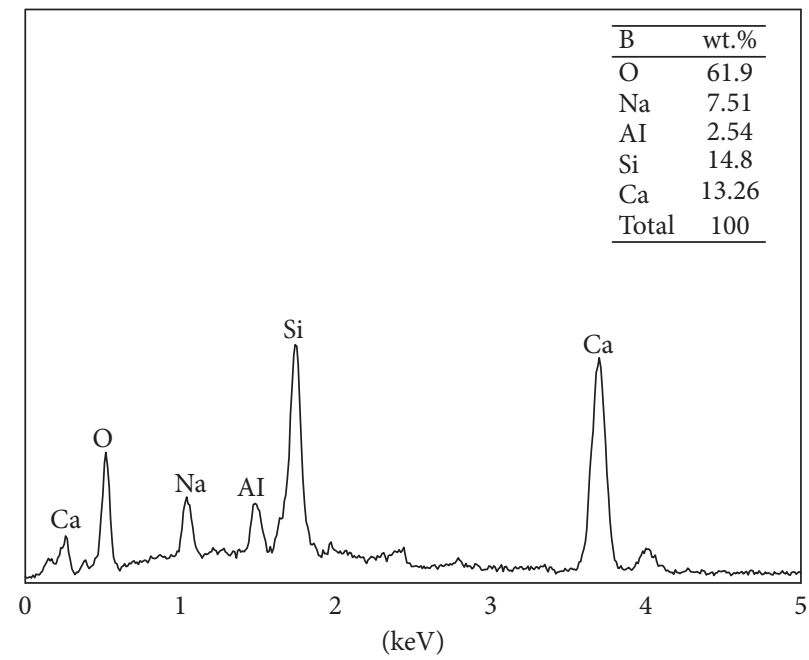

(c)

FIGURE 9: SEM/EDS analysis of the geopolymer specimens at 75\% FA.

are the major elements and $\mathrm{Al}$ is minor (2.54 wt.\%). Area A gel has a $\mathrm{Si} / \mathrm{Al}$ of 2.21 close to the chemical composition of the PSS type geopolymer. The $\mathrm{Si} / \mathrm{Al}$ ratio of the geopolymeric gel is larger than the initial $\mathrm{Si} / \mathrm{Al}$ ratio of the $\mathrm{FA}$ powder, which indicates that $\mathrm{Al}$ is likely to be dissolved and transported to the other phases after dissolution. In the area $\mathrm{B}$, the phase could be some form of CSH. Yip et al. [33] found that the CSH formed in a $\mathrm{NaOH}$-activated metakaolin/slag has a $\mathrm{Ca} / \mathrm{Si}$ ratio of approximately 1, while Lecomte et al. [34] reported the $\mathrm{Ca} / \mathrm{Si}$ is even smaller than 0.7 . The $\mathrm{Ca} / \mathrm{Si}$ ratio of area $\mathrm{B}$ is 0.90 , which falls in the range of existing $\mathrm{Ca} / \mathrm{Si}$ values. The highest UCS gained at the $75 \%$ FA can be attributed to the simultaneous formation of the two phases which fills the voids between these phases leading to a more dense binder.

\section{Conclusions}

This paper investigates the feasibility of using fly ash to enhance ground waste concrete-based geopolymer. The effects of $\mathrm{NaOH}$ concentrations, fly ash contents, and curing time on the UCS were studied. Microstructure and phase compositions are also presented based on the SEM/EDS, XRD, and FTIR analysis. The following conclusions can be drawn:

(1) Increased $\mathrm{NaOH}$ concentration leads to higher UCS because of the larger dissolution of $\mathrm{Si}$ and $\mathrm{Al}$ and the formation of $\mathrm{CSH}$; further increase of $\mathrm{NaOH}$ concentration results in no increase or decrease of UCS.

(2) Addition of fly ash leads to the decrease of $\mathrm{Si} / \mathrm{Al}$ ratio and $\mathrm{Ca}$ content reaching to the optimum ranges and thus improves the UCS of ground waste concretebased geopolymer.

(3) The geopolymers have a significant increase in strength in the first 3 days and gained their maximum strength at 7 days. Almost no change in strength takes place after 7 days.

(4) The simultaneous formation of geopolymeric gel and $\mathrm{CSH}$ gel is responsible for the UCS increase. 


\section{Data Availability}

The authors agree to make freely available any materials and information described in their manuscript that may be reasonably requested by others. Readers can access the data through the following link. https://figshare.com/s/ 27a2206058fc260b19e1.

\section{Conflicts of Interest}

The authors declare that they have no conflicts of interest.

\section{Acknowledgments}

The authors wish to acknowledge the financial support of Transportation Science and Technology Foundation of Jiangsu (no. 8821000039). Dr. Zhen Tang and Engineer Kewei Tan at the Province Key Laboratory of Urban Underground Engineering \& Environmental Safety are gratefully acknowledged for carrying out SEM/EDS and XRD analyses.

\section{References}

[1] L. Moretti and S. Caro, "Critical analysis of the life cycle assessment of the Italian cement industry," Journal of Cleaner Production, vol. 152, pp. 198-210, 2017.

[2] F. N. Stafford, A. C. Dias, L. Arroja, J. A. Labrincha, and D. Hotza, "Life cycle assessment of the production of Portland cement: a Southern Europe case study," Journal of Cleaner Production, vol. 126, pp. 159-165, 2016.

[3] M. Schneider, M. Romer, M. Tschudin, and H. Bilio, "Sustainable cement production-present and future," Cement and Concrete Research, vol. 41, no. 7, pp. 642-650, 2011.

[4] C. T. Formoso, L. Soibelman, C. De Cesare, and E. L. Isatto, "Material waste in building industry: main causes and prevention," Journal of Construction Engineering and Management, vol. 128, no. 4, pp. 316-325, 2002.

[5] H. K. Kanare and P. B. West, "Leachability of selected chemical elements from concrete," in Proceedings of Symposium on Cement and Concrete in the Global Environment, Chicago, IL, USA, 2005.

[6] F. Pacheco-Torgal, V. Tam, J. Labrincha, Y. Ding, and J. de Brito, Handbook of Recycled Concrete and Demolition Waste, Elsevier, Cambridge, UK, 2013.

[7] J. De Brito and N. Saikia, Recycled Aggregate in Concrete: Use of Industrial, Construction and Demolition Waste, Springer Science and Business Media, Berlin, Germany, 2012.

[8] D. R. Hack and D. P. Bryan, Industrial Minerals and Rocks, E. K. Kogel, N. C. Trivedi, and J. M. Barker, Eds., Society for Mining, Englewood, CO, USA, 2006.

[9] W. Lager, "Sustainability of aggregates in construction," in Sustainability of Construction Materials, J. M. Khatib, Ed., pp. 1-30, CRC Press, Boca Raton, FL, USA, 2009.

[10] A. Abbas, G. Fathifazl, O. B. Isgor, A. G. Razaqpur, and S. Foo, "Proposed method for determining the residual mortar content of recycled concrete aggregates," Journal of ASTM International, vol. 5, no. 1, article 101087, 2008.

[11] M. S. Juan and P. A. Gutierrez, "Study on the influence of attached mortar content on the properties of recycled concrete aggregate," Construction and Building Materials, vol. 23, no. 2, pp. 872-877, 2009.
[12] K. Yanagibashi, K. Inoue, S. Seko, and D. Tsuji, “A study on cyclic use of aggregate for structural concrete," in Proceedings of Action for Sustainability: The 2005 World Sustainable Building Conference, Tokyo, Japan, September 2005.

[13] F. Tomosawa and T. Noguchi, "Towards completely recyclable concrete," in Integrated Design and Environmental Issues in Concrete Technology, K. Sakai, Ed., pp. 263-272, Taylor \& Francis, London, UK, 1996.

[14] J. R. Costes, C. Majcherczyk, and I. P. Binkhorst, Total Recycling of Concrete, 2007, http://omogine.blogspot.com/.

[15] J. Xie and O. Kayali, "Effect of initial water content and curing moisture conditions on the development of fly ash-based geopolymers in heat and ambient temperature," Construction and Building Materials, vol. 67, pp. 20-28, 2014.

[16] C. J. Tsai, R. Huang, W. T. Lin, and H. N. Wang, "Mechanical and cementitious characteristics of ground granulated blast furnace slag and basic oxygen furnace slag blended mortar," Materials and Design, vol. 60, pp. 267-273, 2014.

[17] F. Pacheco-Torgal, J. Castro-Gomes, and S. Jalali, "Properties of tungsten mine waste geopolymeric binder," Construction and Building Materials, vol. 22, no. 6, pp. 1201-1211, 2008.

[18] K. Komnitsas, D. Zaharaki, A. Vlacho, and G. Bartzas, "Effect of synthesis parameters on the quality of construction and demolition wastes (CDW) geopolymers," Advanced Powder Technology, vol. 26, no. 2, pp. 368-376, 2015.

[19] W. Chen and Z. Zhu, "Synthesis and characterization of metakaolin modified waste concrete-based geopolymer," in Proceedings of the 2nd International Symposium on Asia Urban GeoEngineering, Changsha, China, November 2017.

[20] H. Xu and J. S. T. Van Deventer, "The geopolymerisation of alumino-silicate minerals," International Journal of Mineral Processing, vol. 59, no. 3, pp. 247-266, 2000.

[21] S. Ahmari, X. Ren, V. Toufigh, and L. Zhang, "Production of geopolymeric binder from blended waste concrete powder and fly ash," Construction and Building Materials, vol. 35, pp. 718-729, 2012.

[22] M. R. Rowles and B. H. O'Connor, "Chemical optimization of the compressive strength of aluminosilicate geopolymers synthesized by sodium silicate activation of metakaolinite," Journal of Materials Chemistry, vol. 13, no. 5, pp. 1161-1165, 2003.

[23] M. R. Rowles and B. H. O’Connor, "Chemical and structural microanalysis of aluminosilicate geopolymers synthesized by sodium silicate activation of metakaolinite," Journal of the American Ceramic Society, vol. 92, no. 10, pp. 2354-2361, 2009.

[24] M. L. Granizo, S. Alonso, M. T. Blanco-Varela, and A. Palomo, "Alkaline activation of metakaolin: effect of calcium hydroxide in the products of reaction," Journal of the American Ceramic Society, vol. 85, no. 1, pp. 225-231, 2002.

[25] S. Alonso and A. Palomo, "Calorimetric study of alkaline activation of calcium hydroxide-metakaolin solid mixtures," Cement and Concrete Research, vol. 31, no. 1, pp. 25-30, 2001.

[26] J. Temuujin, A. Van Riessen, and R. Williams, "Influence of calcium compounds on the mechanical properties of fly ash geopolymer paste," Journal of Hazardous Materials, vol. 167, no. 1-3, pp. 2212-2219, 2009.

[27] M. Steveson and K. Sagoe-Crentsil, "Relationships between composition, structure and strength of inorganic polymers, part I-metakaolin-derived inorganic polymers," Journal of Materials Science, vol. 40, no. 8, pp. 2023-2036, 2005.

[28] Z. Yunsheng, S. Wei, and L. Zongjin, "Composition design and microstructural characterization of calcined kaolin-based 
geopolymer cement," Applied Clay Science, vol. 47, no. 3-4, pp. 271-275, 2010.

[29] P. Duxson, J. L. Provis, G. C. Lukey, S. W. Mallicoat, W. M. Kriven, and J. S.J. van Deventer, "Understanding the relationship between geopolymer composition, microstructure and mechanical properties," Colloids and Surfaces A: Physicochemical and Engineering Aspects, vol. 269, no. 1-3, pp. $47-58,2005$.

[30] J. W. Phair, J. S. J. Van Deventer, and J. D. Smith, "Mechanism of polysialation in the incorporation of zirconia into fly ashbased geopolymers," Industrial and Engineering Chemistry Research, vol. 39, no. 8, pp. 2925-2934, 2000.

[31] V. D. Glukhovsky, "Ancient, modern and future concretes," in Alkaline Cements and Concrete, P. V. Krivenko, Ed., CRC Press, Ukraine, 1994.

[32] M. Frias and J. Cabrera, "Influence of MK on the reaction kinetics in MK/lime and MK-blended cement systems at $20^{\circ} \mathrm{C}$," Cement and Concrete Research, vol. 31, no. 4, pp. 519-527, 2001.

[33] C. K. Yip, G. C. Lukey, and J. S. J. Van Deventer, "The coexistence of geopolymeric gel and calcium silicate hydrate at the early stage of alkaline activation," Cement and Concrete Research, vol. 35, no. 9, pp. 1688-1697, 2005.

[34] I. Lecomte, C. Henrist, M. Liegeois, A. Rulmont, and R. Cloots, "Microstructural comparison between geopolymers, alkali-activated slag cement and Portland cement," Journal of the European Ceramic Society, vol. 26, no. 16, pp. 3789-3797, 2006.

[35] A. Fernandez-Jimenez, F. Puertas, I. Sobrados, and J. Sanz, "Structure of calcium silicate hydrates formed in alkalineactivated slag: influence of the type of alkaline activator," Journal of the American Ceramic Society, vol. 86, no. 8, pp. 1389-1394, 2003.

[36] J. G. S. Van Jaarsveld, J. S. J. Van Deventer, and G. C. Lukey, "The effect of composition and temperature on the properties of fly ash and kaolinite-based geopolymers," Chemical Engineering Journal, vol. 89, no. 1-3, pp. 63-73, 2002.

[37] J. G. S. Van Jaarsveld and J. S. J. Van Deventer, "Effect of the alkali metal activator on the properties of fly ash-based geopolymers," Industrial and Engineering Chemistry Research, vol. 38, no. 10, pp. 3932-3941, 1999.

[38] W. K. W. Lee and J. S. J. Van Deventer, "Use of infrared spectroscopy to study geopolymerization of heterogeneous amorphous aluminosilicates," Langmuir, vol. 19, no. 21, pp. 8726-8734, 2003.

[39] A. Allahverdi and E. N. Kani, "Construction wastes as raw materials for geopolymer binders," International Journal of Civil Engineering, vol. 7, no. 3, pp. 154-160, 2009.

[40] X. Guo, H. Shi, and W. A. Dick, "Compressive strength and microstructural characteristics of class C fly ash geopolymer," Cement and Concrete Composites, vol. 32, no. 2, pp. 142-147, 2010.

[41] J. Davidovits, "Geopolymer chemistry and properties," in Proceedings of the First European Conference on Soft Mineralogy, J. Davidovits and J. Orlinsl, Eds., The Geopolymer Institute, pp. 25-48, Compiegne, France, 1988. 


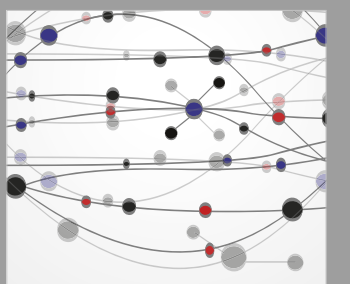

The Scientific World Journal
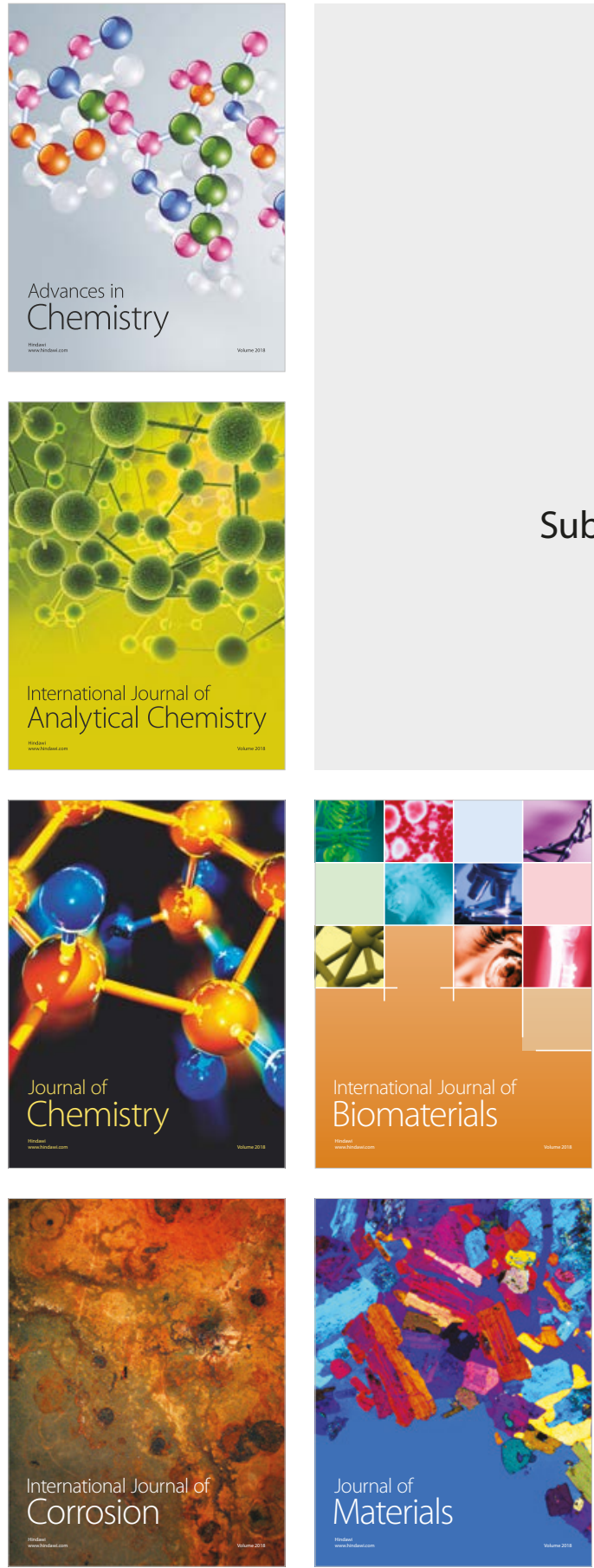

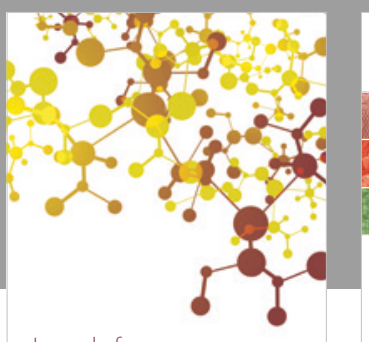

Journal of

Applied Chemistry
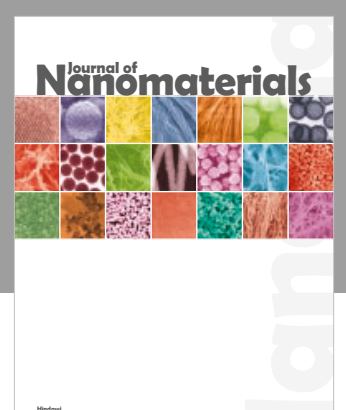

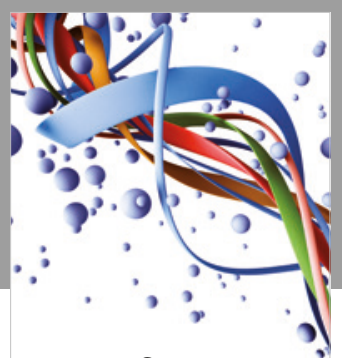

Scientifica

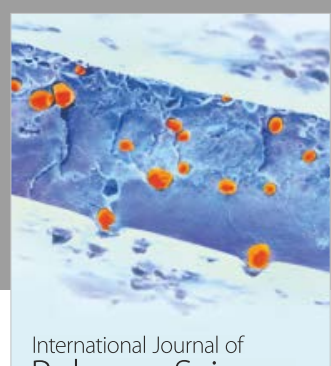

Polymer Science

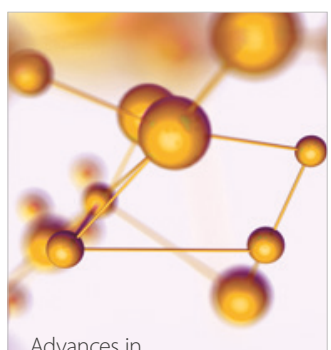

Physical Chemistry
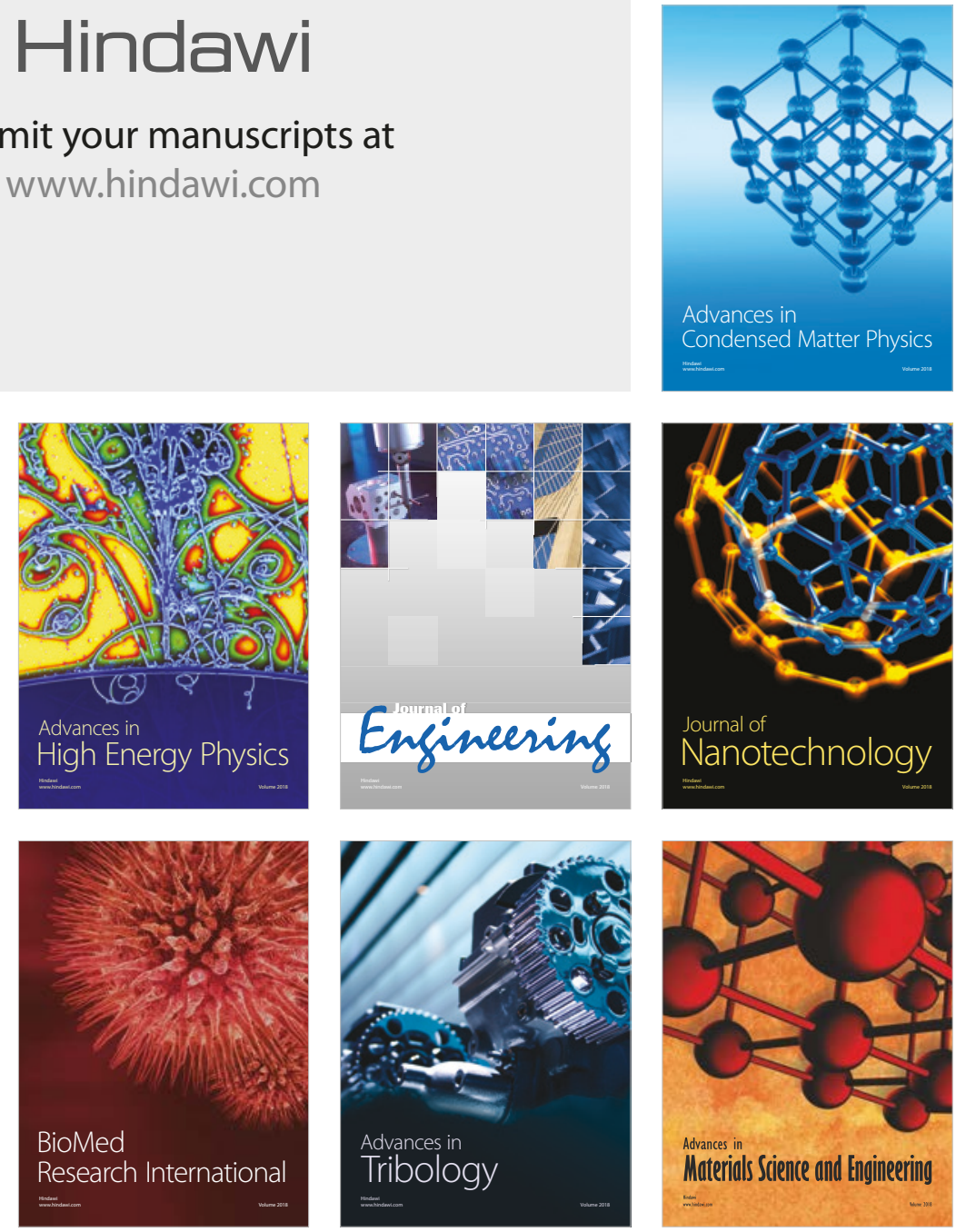